\section{SPECIAL CARE DENTISTRY}

\section{Oral health status and dental service use of adults with learning disabilities living in residential institutions and in the community}

Tiller S, Wilson Kl et al. Community Dent Health 2001; 18: 167-171

This comparison in Sheffield suggests that adults in residential care (RC) have better dental care than those living in the community (C).

This study examined 209 subjects (14\% of those on the Sheffield learning disability register), and 130 of these were living in the community, which has significant benefits for learning disabled people. In respect of decay, mean DT was 0.7 for RC subjects and 1.6 for $C$ dwellers $(P<0.01)$, MT was 10.1 and $7.5(P<0.05)$, and FT was 3.5 and 3.9 (NS). Overall caries experience was similar in $\mathrm{RC}$ and $\mathrm{C}$ subjects, and similar to the general population, but with higher MT and lower FT. RC subjects had more plaque $(P<0.01)$.

Similar proportions of $\mathrm{RC}$ and $\mathrm{C}$ subjects used the GDS for treatment, but more $\mathrm{RC}$ than $\mathrm{C}$ subjects used the CDS $(P<0.01)$. While only $6 \%$ of RC subjects had no dentist, 33\% of C subjects were in this category. Regular attendance was reported by $85 \%$ of RC and 55\% of $C$ subjects $(P<0.001) ; 10 \%$ of RC and 30\% of $C$ attended only with problems. The authors recommend targetting the $\mathrm{C}$ group.

\section{TRAUMA: ASSAULT}

\section{Maxillofacial injuries associated with domestic violence}

Le BT, Dierks EJ et al. J Oral Maxillofac Surg 2001; 59: 1277-1283

Most domestic violence injuries are maxillofacial: $81 \%$ in this study.

This was a retrospective review of 236 patients, with a history of intentional assault by spouse or partner, seen over a 5 year period in a level 1 trauma hospital in Oregon. Mean age was 31 yrs (range 15-71), and all were female. Nearly 4/5 were single, separated or divorced, and 3/4 were unemployed; alcohol was involved in 1/3 cases, and 3/5 had a drug abuse history; 9 were pregnant.

There were altogether 257 contusions and abrasions (61\% maxillofacial), 70 lacerations (40 needing repair) and 93 fractures (85 facial) and dislocations. More than $2 / 3$ of fractures affected the middle face and 2/3 of these included nasal fracture. Injuries were mainly by fists (67\%) and blunt weapons (15\%). In a following discussion, a Scottish surgeon asks whether it may be possible to change the social factors involved.

\section{CONSERVATIVE DENTAL SURGERY}

\section{Removal of fractured posts using ultrasonic vibration: an in vivo study}

\section{Smith BJ J Endodon 2001; 27: 632-634}

Post removal in vivo is much quicker than previous studies in vitro suggested.

In 16 male and 14 female patients of mean age 51 yrs (range 2570) with fractured non-screw type posts, removal was achieved with an ultrasonic scaler. Previous studies on this subject have all been performed in vitro. A $2 \mathrm{~mm}$ gutter was prepared round each post with a fine diamond bur, the scaler was applied for periods of $15 \mathrm{sec}$, separated by $30 \mathrm{sec}$. Posts were then tested and removed when loose.

The mean ultrasonic vibration time to loosen posts was 2.05 $\min (0.25-6.0)$ and removed fragments were a mean $3.78 \mathrm{~mm} \mathrm{(0.5-}$ 6.8) long and $1.16 \mathrm{~mm}(0.8-1.5)$ diameter. There was significant correlation of vibration time with fragment length $(\mathrm{r}=0.52 ; P=$ $0.003)$, but not with diameter $(\mathrm{r}=0.35 ; P=0.059)$. Vibration time was about $25 \%$ of that found in studies in vitro, perhaps because of differences in cementation.

\section{PAEDODONTICS; OTOLOGY}

\section{Pacifier use and the occurrence of otitis media in the first year of life}

Warren JJ, Levy SM et al. Pediatr Dent 2001; 23: 103-107

\section{Pacifier use is a modifiable risk factor for otitis media (OM).}

$\mathrm{OM}$ is a frequent problem in early life, with significant health care costs. Of a cohort of 1882 mothers in a dental study in Iowa, 1375 provided information during the first year of their children's lives, with response declining to 792 by the last questionnaire. During the year, the reported prevalence of $0 \mathrm{M}$ was $72 \%$, and it was much commoner in the second six months of life.

Significant risk factors for OM included male gender $(\mathrm{OR}=$ 1.19) and use of a pacifier (1.2). Factors which were not significant included tobacco use in the home, breastfeeding and digit sucking alone. When this study was compared with the results of other studies, pacifier use appeared a constant risk factor for OM; the authors consider the high prevalence of OM means that reducing pacifier use will have a useful effect. 